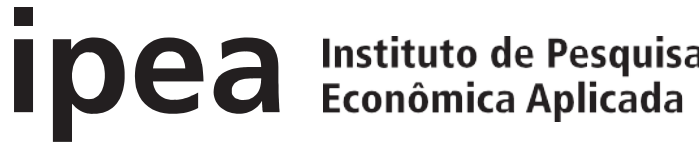

Título do capítulo

Autores(as)

DOI

Título do livro

Organizadores(as)

Volume

Série

Cidade

Editora

Ano

Edição

ISBN

DOI
CAPÍTULO 2

INDÚSTRIA E TERRITÓRIO NO BRASIL: DEBATES, EVIDÊNCIAS

E HIPÓTESES PARA UMA ANÁLISE CONTEMPORÂNEA

Aristides Monteiro Neto

https://dx.doi.org/10.38116/978-65-5635-020-2/cap2

BRASIL, BRASIS: RECONFIGURAÇÕES TERRITORIAIS DA INDÚSTRIA NO SÉCULO XXI

Aristides Monteiro Neto

Brasilia

Ipea

2021

$1^{3}$

978-65-5635-020-2

https://dx.doi.org/10.38116/978-65-5635-020-2 


\title{
INDÚSTRIA E TERRITÓRIO NO BRASIL: DEBATES, EVIDÊNCIAS E HIPÓTESES PARA UMA ANÁLISE CONTEMPORÂNEA
}

\author{
Aristides Monteiro Neto'
}

\section{INTRODUÇÃO}

A reflexão a que se propóe o livro Brasil, Brasis: reconfiguraçôes territoriais da indústria no século XXI refere-se fundamentalmente ao tema da mudança ou transformaçáo estrutural da economia brasileira em perspectiva territorial. Não é, portanto, um estudo exclusivo sobre mudanças setoriais recentes e muito menos apenas sobre disparidades regionais per se. Pelo contrário, seu intento é analisar o percurso realizado pela atividade industrial no território brasileiro no período recente, delimitado pelos anos de 1995 a 2018, em linha com a trajetória longamente estabelecida de desenvolvimento da economia brasileira comandada pelo impulso industrializante.

Nesta pesquisa, adotou-se o método histórico-estrutural como base explicativa para os processos em curso a cada momento. Isto é, reconheceram-se as trajetórias de dependência institucionais, políticas e econômicas que circundam as ações e escolhas dos atores econômicos em torno das oportunidades de ganho entre tipologias de atividades produtivas, sendo a atividade industrial uma delas. Os elementos da estrutura produtiva industrial contemporânea aqui investigados são localizados frente à sua trajetória histórica e confrontados quanto a certas teses enraizadas na literatura especializada.

Este estudo é, intencionalmente, um ensaio de desenvolvimento econômico regional ou territorial. Reconhece-se aqui o papel historicamente estabelecido pela centralidade da indústria no processo de concentração produtiva no território brasileiro a partir da economia de Sáo Paulo, bem como se entende o papel que aquele setor exerceu na integraçáo de mercados regionais relativamente autônomos em um mercado de escala nacional com articulaçóes regionais complexas. Desse modo, lançam-se luzes sobre a atualidade deste papel diante do notório enfraquecimento da dinâmica produtiva da indústria nas últimas duas décadas. Algumas respostas para as questões lançadas neste trabalho foram dadas, mas, sempre que possível, questionamentos foram realizados e veios de investigaçóes futuras ficaram em aberto.

1. Técnico de planejamento e pesquisa na Diretoria de Estudos e Políticas Regionais, Urbanas e Ambientais (Dirur) do Ipea e organizador deste livro. E-mail: <aristides.monteiro@ipea.gov.br>. 
Este trabalho tem como objeto de estudo o território; os setores investigados são perscrutados quanto à sua dinâmica de localização territorial: por que se localizam aqui ou acolá? Por que se transferiram de um lugar para outro? Por que apenas se desenvolvem aqui e não acolá? Entende-se que as atividades produtivas (plantas industriais) não apenas se localizam ou se transferem para uma dada regiâo por motivaçóes de tamanho de mercado, expansão da renda interna regional etc., mas também frequentemente se tornam impelidas a novas localizaçôes por estímulos de políticas econômicas - quer sejam produtivas, quer sejam regionais - na forma de incentivos fiscais, financeiros, facilitaçôes na provisão de infraestrutura, entre outras.

Muitas das respostas a essas questôes foram dadas por estudiosos brasileiros em momentos pregressos, várias outras têm sido respondidas no momento presente. Tenta-se neste estudo apresentar ora um alinhamento possível, ora um confronto desejável destas soluçóes. Estabelece-se ainda um debate entre teses e resultados observáveis levando-se em conta uma certa leitura própria de processos e estatísticas especialmente trabalhados para este propósito.

Alguns questionamentos de referência para as análises desenvolvidas nos vários capítulos deste livro podem ser sumariamente antecipados a seguir. Estes, ao seu modo, representam desenvolvimentos teóricos consolidados e se prestam agora à investigação do momento atual.

1) Que tipo de mudança estrutural pode ser associado à indústria brasileira nestas duas décadas (1995-2018) de ajustamento ao ambiente de abertura comercial, de liberalização financeira e expansão da demanda mundial por commodities agrominerais?

2) Em que medida a estrutura industrial prevalecente se aproxima ou se distancia de um vetor de dinamização (expansão e diversificação da renda interna, diversificaçáo do mercado de trabalho, aumento da produtividade e da competitividade) para os demais setores de atividade, desde a agropecuária até as atividades terciárias, tal como operou durante pouco mais de meio século, grosso modo, entre 1930 e 1980, como situa a literatura pertinente (Cano, 1985), na economia brasileira?

3) Qual o padrão de ocupação do território e de disparidades regionais associado ao desenvolvimento recente da indústria? Em particular, há um esforço em se verificar a validade ou alteração do alcance de teses consagradas no debate regional brasileiro, tais como: i) integração do mercado nacional (Cano, 1985; 1998; Pacheco, 1998); ii) desconcentração concentrada (Diniz, 1993); e iii) crescimento regional desigual e heterogêneo (Araújo, 2000; Brandão, 2007; Macedo, 2010). 
4) O que as transformaçóes recentes na estrutura industrial e suas demandas por localização territorial têm a dizer às políticas de desenvolvimento regional ainda muito centradas no ideal industrializante para as regióes "periféricas"?

Apresentadas as principais preocupaçôes e, portanto, vislumbradas as questôes centrais do debate empreendido nas várias partes deste estudo, o esforço aqui realizado deve considerar em primeiro lugar como se configura historicamente o problema regional em sua inter-relação com a expansão industrial no caso brasileiro. A explicação se desdobra em três fases ou periodizaçôes, as quais apresentam o essencial da configuração territorial prevalecente motivada pela gênese, pelo desenvolvimento e pela crise da atividade industrial. ${ }^{2}$

\section{DIMENSÃO TERRITORIAL DA EVOLUÇÃO DA INDÚSTRIA BRASILEIRA}

\subsection{Primeira fase (1930-1970): gênese e expansão da indústria com concentração produtiva regional}

No longo período iniciado em, aproximadamente, 1930 e demorando-se até a década de 1970, o Brasil viu uma significativa transformação de sua estrutura produtiva. Situa-se neste longo século a gênese, o florescimento e a consolidação de sua economia industrial. De uma economia assentada em complexos agroexportadores, viu-se constituir no estado de São Paulo, a partir da expansão da atividade do café, a transição para uma economia de base industrial.

Em seu processo de consolidação, a economia industrial viria a impulsionar e ser mutuamente alimentada - por uma acelerada urbanização da sociedade brasileira e a constituir plenamente a integraçáo do mercado nacional até então composto por economias regionais relativamente autônomas e com baixo nível de trocas econômicas entre si (Cano, 1985).

Na perspectiva da dinâmica territorial, a economia paulista comandou o processo de industrialização e reteve em seu território, no auge dos anos 1970, mais da metade do produto industrial nacional. A indústria de transformação em São Paulo passou de 40,7\% para 58,2\% do total nacional entre 1939 e 1970 (Cano, 2011). As disparidades regionais do produto interno bruto (PIB) e da produção industrial que vinham aumentando de maneira muito perceptível desde a década de 1940 atingiram seu ponto máximo em 1975, quando, a partir de então, passaram a apresentar redução.

Em concomitância ao processo de industrialização acelerada, o desenvolvimento urbano se tornou também frenético. Houve a consolidação de parte mais representativa da população brasileira na região Sudeste e em especial no estado de

2. Essa periodização segue, grosso modo e de maneira bem resumida, a literatura sobre a integração do mercado nacional longamente desenvolvida por Wilson Cano em diversos trabalhos (Cano, 1985; 1998; 2011). 
São Paulo, que passou de 13,1\% da população nacional em 1900 para 17,4\% em 1940 e 20,9\% em 1980. Em 2010, a população desse estado era de 21,6\% e ele continuava estabelecido como o mais populoso do país. Sua capital, a cidade de São Paulo, tornou-se o epicentro econômico e populacional nacional na primeira metade do século passado: com 239,8 mil habitantes em 1900, a cidade chegou a 1,3 milhão em 1940 e 3,8 milhóes em 1960 - nesse último ano, a população do município teria ultrapassado a do município do Rio de Janeiro, ex-capital federal (IBGE, [s.d.]).

\subsection{Segunda fase (1970-1990): consolidação da indústria com desconcentração produtiva regional}

Os estudos sobre desigualdades regionais passaram a evidenciar trajetórias de desconcentração produtiva apenas a partir de 1970. Teria sido, na verdade, entre 1970 e 1985 que a economia de São Paulo reduziu sua participação relativa na economia nacional e as regiôes "periféricas" do Norte (NO), Nordeste (NE) e Centro-Oeste (CO), por sua vez, iniciaram uma trajetória de ganhos relativos (Cano, 1998).

A partir desse momento, os estudos regionais estiveram centrados em explicar a intensidade e a motivação para a desconcentração produtiva em curso. As razóes mais presentes na literatura estão relacionadas, de um lado, às crescentes deseconomias de aglomeração na Região Metropolitana (RM) de São Paulo, que levaram a um vetor de localização no seu interior e aos estados das regiōes Sudeste e Sul; e, de outro lado, à firme ação estatal federal, ainda na década de 1970, na forma de vultosos investimentos em infraestrutura dos planos nacionais de desenvolvimento (PNDs) I e II nas regiôes Norte, Nordeste e Centro-Oeste.

Somaram-se a esses dois vetores os crescentes recursos destinados a incentivos fiscais e financeiros das políticas regionais dos governos militares nas regiōes de menor desenvolvimento, os quais, sem dúvida, impulsionaram o deslocamento de capitais produtivos para as regióes periféricas, elevando assim a sua participação relativa no PIB nacional.

Pode-se, na verdade, afirmar que o processo de desconcentração regional da atividade produtiva tem um forte componente de indução do planejamento governamental, pois, mesmo em contexto de elevada expansão do produto industrial e da urbanização nas regiōes mais avançadas do país, as regióes-alvo de políticas regionais puderam aumentar sua participação na economia nacional.

\subsection{Terceira fase (pós-1990 e até os dias atuais): desindustrialização com desconcentração produtiva regional}

No fim da década de 1980 e início dos anos 1990, instalou-se uma profunda crise financeira e fiscal na economia brasileira, motivada pela acelerada expansão do endividamento externo e da drenagem de recursos para o pagamento dos 
compromissos (juros e serviços da dívida) junto a credores externos. Uma de suas manifestações mais graves foi a desestruturação das finanças governamentais federais e a consequente suspensão dos seus planos de investimento. $\mathrm{O}$ processo de desconcentração produtiva regional que começava a se consolidar até então passou a ser visto como incógnita.

No início dos anos 1990, reformas econômicas (Planos Collor I e II) foram executadas tendo como cerne a abertura comercial e financeira da economia brasileira. As restriçóes e medidas de proteção do mercado interno sofreram bruscas reduçóes com o objetivo de promover um choque de produtividade na estrutura produtiva nacional.

A partir de 1995, com a implementação do Plano Real de estabilização econômica, as desregulamentaçôes tarifárias e da conta de capital tiveram novo reforço. As importaçóes de insumos e produtos industrializados iniciaram uma trajetória de expansão significativa desde então. Um processo acelerado de privatizaçôes de empresas públicas ganhou momento, o que resultou em redefinição do tamanho (para menos) do estado como produtor de bens e serviços no país.

É nesse contexto que se instala a percepção de um processo de enfraquecimento paulatino da atividade industrial no conjunto da economia nacional. Premida pela fraqueza do mercado interno em crise e pela superior competitividade (custo inferior e/ou superior capacidade tecnológica) de competidores externos, a indústria vem perdendo participação relativa no PIB nacional.

A premissa que se tem assentado na literatura sobre a estrutura produtiva doméstica nessa última etapa é a do fim de um ciclo histórico em que a industrialização foi o motor do crescimento e das transformaçóes da economia nacional. Contrariamente ao que ocorreu nos países desenvolvidos, onde a desindustrialização se instalou juntamente com o aumento da relevância e sofisticação das atividades terciárias, no Brasil, o processo de desindustrialização se estabeleceu precocemente em nível de PIB per capita ainda muito baixo e associado a atividades terciárias de reduzido valor agregado e produtividade.

Em perspectiva territorial, a perda de relevância da indústria não ocorre para todas as regióes e em algumas o produto industrial tem até mesmo aumentado. Contudo, os encadeamentos intersetoriais e inter-regionais em atividade produtivas à montante e à jusante têm se mostrado mais fracos. Este processo está alinhado com as modificaçóes no capitalismo global, em curso desde os anos 1990, em direção ao comando da esfera produtiva pela financeira, conforme apontaram Coutinho e Beluzzo (1996), o qual leva a profundas alteraçóes sobre a inserçáo de países como o Brasil neste novo sistema. Para países da periferia, os graus de autonomia sobre a política econômica - e, portanto, sobre suas trajetórias de desenvolvimento se reduzem enormemente. Neste contexto, as naçóes em desenvolvimento estão 
fadadas a se esforçar para criar as condições necessárias à atração de capitais; suas estratégias se tornam passivas e dependentes de massas externas de capital.

A reorganizaçáo global, de um lado, alocando os setores intensivos em conhecimento e elevada densidade capital nos países centrais e, de outro lado, destinando as atividades intensivas em recursos naturais e minerais nos países da periferia ficou mais e mais evidente e consolidada. Desse modo, o modelo brasileiro de inserção externa tem se configurado no sentido de produzir e exportar uma pauta generalizada de bens primários ou intensivos em tecnologia de processamento de recursos naturais. O estudo de Macedo (2010), sobre as transformaçóes operadas pela ampliação das atividades destinadas à exportação em diversas regiôes do país no período 1989-2008, sinalizou amplamente para tal padrão de produção de baixo valor agregado, baixas relaçóes intersetoriais e níveis salariais e de rendimentos igualmente inferiores e concentrados.

A trajetória de desindustrialização ou da chamada regressão produtiva permanece até os dias atuais e será objeto de reflexão aprofundada neste estudo. Em particular, o interesse prevalecente é apresentar evidências e propor algumas explicaçóes para os impactos e as consequências das transformações da indústria na ocupação do território e nas disparidades regionais.

\section{MANIFESTAÇÕES E CONSEQUÊNCIAS DA REESTRUTURAÇÃO PRODUTIVA ATUAL: ELEMENTOS INFORMATIVOS DO DEBATE ACADÊMICO}

\subsection{Desindustrialização natural ou precoce? Interpretações ortodoxa versus heterodoxa da questão}

O debate sobre as forças do desenvolvimento econômico esteve inicialmente nos anos 1940/1950 centrado na atribuiçâo de um papel relevante do setor industrial para a consolidação e expansão das economias nacionais. Lewis (1954), Myrdal (1957) e Kaldor (1966; 1970), entre outros, foram autores que advogavam o papel mais estratégico da indústria para a modernização econômica. As economias desenvolvidas da Europa e da América do Norte no pós-guerra se caracterizavam pela diminuição da importância relativa do setor agrícola e pelo aumento concomitante das atividades industriais. Como apontou Kaldor, as atividades industriais, por apresentarem economias de escala muito robustas, elevam a produtividade geral da economia pelo impulso que geram dentro da própria indústria e para fora nos setores agrícola e de serviços.

$\mathrm{Na}$ América Latina, as teses tiveram forte recepção, no âmbito dos estudos patrocinados pela Comissão Econômica para a América Latina e o Caribe (CEPAL), de Furtado (1961) e Prebisch (1949) no início dos anos 1960. As estratégias de desenvolvimento sugeridas para os países latino-americanos deveriam sustentar uma 
mudança estrutural lastreada na industrialização nacional que deveria ser capaz de superar as perdas de troca no comércio internacional geradas pela dependência em atividades agroexportadoras, ao mesmo tempo que também deveria ser capaz de alterar o elevado peso das atividades de subsistência no conjunto das atividades pelo aumento de sua produtividade.

O Brasil, assim como o México e a Argentina, foi um dos países que mais esforços realizou para se industrializar durante o século XX. A estrutura produtiva de fato passou a conter mais ramos de atividades industriais, conseguindo até mesmo implantar alguns núcleos de indústrias produtoras de bens de capital. A produção industrial expandiu-se com força desde a década de 1930 até os anos 1980.

Apesar disso, a partir da década de 1990, a tendência predominante foi o arrefecimento da atividade industrial como elemento dinâmico da economia. Os dados de contas regionais, do Instituto Brasileiro de Geografia e Estatística (IBGE), sobre o valor adicionado bruto $(\mathrm{VAB})$ da indústria de transformação apresentaram nítida tendência de redução no VAB total da economia: de 18,6\% do total em 1995, para 17,2\% em 2000, 15,0\% em 2010 e, finalmente, 12,4\% em 2017.

$\mathrm{O}$ enfraquecimento da indústria brasileira tornou-se assunto de intensa avaliação por especialistas. Dois grupos de visôes predominantes e posiçóes contrastantes podem ser apontados. No primeiro grupo, economistas de matiz ortodoxa, os quais se alinharam à percepção de que a desindustrialização brasileira ocorre em trajetória similar à que está acontecendo em economias maduras da Europa, dos Estados Unidos e do Japão.

Para esse grupo de estudiosos, o processo em curso constitui uma evolução natural do desenvolvimento setorial e o esforço a ser perseguido no momento é de fortalecimento ou estímulo aos setores terciários ditos modernos de elevada produtividade. Para esses autores, assim como no passado houve a transferência de recursos produtivos e capitais da agricultura (setor de mais baixa produtividade) para a indústria (de maior produtividade), é chegada a hora da transição de uma economia industrial para uma outra lastreada em serviços. São autores que apregoam a existência de um processo natural de transição setorial em sequência na forma agricultura-indústria-serviços (Bacha e De Bolle, 2013). ${ }^{3}$

Em uma economia de mercado, ainda nesta visão, as empresas deveriam realizar apostas de produção e de investimentos nas atividades em que a lucratividade

3. 0 livro organizado por Bacha e De Bolle (2013), intitulado O futuro da indústria no Brasil: desindustrialização em debate, trouxe elementos muito representativos da visão "ortodoxa" sobre a desindustrialização brasileira, a obra não apenas apresentou uma avaliação com dados robustos e atuais, à época, como arregimentou um grupo considerável de expoentes, geralmente do Instituto de Estudos de Política Econômica/Casa das Garças (lepe/CdG) e da Fundação Getulio Vargas (FGV), ambas no Rio de Janeiro, e da Universidade de São Paulo (USP), sobre o assunto. Em particular, 0 artigo de Bonelli, Pessoa e Matos (2013) nessa coletânea, intitulado Desindustrialização no Brasil: fatos e interpretação é bastante significativo sobre a tese em relevo. 
se apresenta mais elevada, qualquer que seja o setor. Em cada momento, a melhor alocação de recursos levará a mais eficiência econômica e maior taxa de crescimento do produto. As transformaçóes da indústria brasileira, caracterizadas pela perda de sua importância relativa, representariam, portanto, um curso natural de mudança do sistema econômico em linha com o que vem acontecendo na economia mundial. O Brasil estaria apenas se ajustando aos estímulos emitidos pelas relaçóes de troca do comércio internacional. A desindustrialização passa a ser vista como fenômeno normal e esperado, sem se constituir em problema grave da política industrial.

As orientaçôes de política derivadas desse raciocínio sugerem que não há muito sentido econômico em apoiar setores econômicos escolhidos. No limite, os capitais se orientarão pelos sinais de rentabilidade emitidos pelo próprio mercado; no atual caso brasileiro, como as atividades terciárias modernas e de produção de agrominerais voltadas para exportação são as mais lucrativas, elas terão a atenção da política econômica preferencialmente apontada para si.

No segundo grupo estão os estudiosos que entendem a maior relevância da indústria em uma dada estrutura produtiva, os que se alinham a teses heterodoxas schumpeterianas e/ou kaldorianas, nas quais a indústria é o motor de crescimento de uma economia, ou a teses cepalinas, em que a indústria é vista como a atividade capaz de alterar a situaçáo de tendência nos termos de troca e de dependência das economias agroexportadoras, ou, ainda, a teses recentes que advogam que países desenvolvidos são aqueles que possuem maior complexidade econômica dada pelo superior número de produtos de elevado valor agregado na estrutura produtiva.

No geral, esses analistas confluem para o entendimento de que a atividade industrial é aquela que produz mais intensa capacidade multiplicadora sobre atividades à frente e para trás (na própria indústria e também na agricultura e nos serviços). Quando analisadas as estruturas produtivas nacionais por meio de matrizes de insumo-produto, por exemplo, os efeitos multiplicadores são sempre notados como mais fortes na indústria de transformação que nos demais setores (Marconi, Rocha e Magacho, 2016; Vital da Costa e Neves, 2016; Mollo e Takasago, 2019).

Esse grupo de pensadores diverge também dos economistas ortodoxos na interpretação do fenômeno da desindustrialização. Para a heterodoxia, a desindustrialização brasileira, ao contrário daquela que ocorre nos Estados Unidos e nos países europeus, é precoce e indesejável. Estabeleceu-se em nível de produto per capita baixo e inferior ao já obtido pelas economias desenvolvidas, o que restringe a capacidade da indústria nacional em produzir reverberaçôes mais ampliadas sobre os demais setores econômicos (Oreiro e Marconi, 2014; Cano, 2012; Sampaio, 2015; Morceiro, 2016).

A orientação de política resultante dessa visão se contrapóe, claramente, à anterior. Advoga-se a necessidade de apoio ao setor industrial, regra geral, 
sugerindo estímulos para o fortalecimento de setores que perderam competitividade internacional, e, mais importante, do esforço para que a estrutura industrial se torne, permanentemente, capaz de incorporar novos ramos de atividade com maior intensidade de capital e de tecnologia.

Considerando que as duas vertentes explicativas contrastantes sobre a desindustrialização e suas consequências estejam solidamente presentes no debate, o ponto crucial é que elas reconhecem, respondem e apontam, cada qual ao seu modo, para o enfrentamento de uma nova e indesejável limitação estrutural para a trajetória futura do desenvolvimento brasileiro. Questão de enorme interesse, por razóes óbvias, para a questão regional.

\subsection{Reestruturação com características de regressão produtiva}

A perda de importância da indústria na economia nacional é absoluta (sua produção diminui) ou é relativa (sua produção perde participação no cenário nacional)? É fundamentalmente um problema relacionado à produção ou está também ligado à capacidade de geração de emprego? Estas são questôes fundamentais do presente debate, as quais se prestam a esclarecer as diversas formas de manifestação em que se apresenta a transformação da indústria brasileira.

Deve-se esclarecer, em primeiro lugar, que as estatísticas confirmam a existência de características de desindustrialização do tipo relativo apenas depois de 2005 no Brasil e ainda não comprovam a desindustrialização absoluta. Os estudos, como os realizados por Nassif (2008), com dados para o período 1990-2005, e Squeff (2012), para o período 2000-2009, constataram fracos sinais de desindustrialização, medidos pela perda de produto e/ou emprego. Contudo, em trabalhos que investigaram a performance industrial em anos mais recentes (com bases de dados após 2010), como os de Morceiro (2016), Arend, Singh e Bicharra (2016) e Sampaio (2015), utilizando estatísticas de produção industrial da Pesquisa Industrial Anual (PIA) do IBGE, as evidências de desindustrialização relativa se tornaram indiscutíveis.

O processo em curso é de enfraquecimento progressivo da cadeia produtiva da indústria. Nota-se que ramos industriais ligados à extrativa crescem em ritmo superior aos da transformação e há flagrante redução do componente tecnológico e de valor agregado no tecido industrial. A existência de um vetor de regressão produtiva está muito evidente na literatura mais recente sobre a indústria, desse modo, ele não se constitui mais em elemento de dúvida ou de indeterminação factual. Sua presença tem estado associada a inúmeras características internas da atividade produtiva, como as identificadas a seguir.

1) Redução do índice de complexidade econômica: sugerido por Gala (2017) em estudo do caso brasileiro em que apresenta a redução da participação 
de bens industriais manufaturados de alto valor agregado e concomitante expansão do número e da importância dos bens agroindustriais e minerais.

2) Redução do índice de densidade produtiva (IDP): dado pela relação entre o valor da transformação industrial (VTI) e o valor bruto da produção industrial (VBPI), isto é, IDP = VTI/VBPI - como observaram Monteiro Neto e Silva (2018).

3) Aumento do componente importado no valor total da produção industrial, conforme observou Sampaio (2015).

4) Redução da interdependência setorial (análise insumo-produto), como assinalado por Vital da Costa e Neves (2016).

5) Baixo crescimento dos índices de produtividade total da indústria e de grupos de indústria investigados, sendo que a indústria de transformação apresentou evolução constante e nível baixo, em torno de $1 \%$ ao ano (a.a.), durante a década de 2000, e a extrativa e agropecuária mostraram evolução superior com taxas de 2,0\% e 3,8\% a.a., respectivamente (Cavalcante e De Negri, 2014). Expandindo a análise com dados posteriores a 2010, Sampaio (2017) e Monteiro Neto e Silva (2018) também confirmam os diferenciais de produtividade em desfavor da indústria.

Outro vetor de observação da regressão industrial também é obtido na investigação de alterações intrarramos por meio de tipologias de avaliação específicas como as seguintes.

6) Estudos sobre intensidade tecnológica de grupos de indústria categorizados em baixa, média, média-alta e alta intensidade cujas avaliações identificam aumento da participaçáo dos grupos de baixa e média intensidade tecnológica e redução da posição dos demais (Sampaio, 2015; Morceiro, 2016).

7) Emprego do recorte intrassetorial em grupos industriais baseados em commodities agrícolas processadas, indústria tradicional, commodities industriais, indústria inovativa e outras (Vital da Costa e Neves, 2016).

8) Emprego da tipologia do fator competitivo em que os grupos industriais são organizados e baseados em recursos naturais, intensivos em mão de obra, intensivos em escala, diferenciados e intensivos em conhecimento, conforme Nassif (2008) realizou para o Brasil e Monteiro Neto e Silva (2018) aplicaram para as estruturas produtivas regionais.

Os elementos citados são representativos de uma configuração de fragilidade do setor industrial que não é conjuntural - posto que vem se consolidando desde a década de 1990 até o presente - e é generalizada por quase todos os ramos de 
atividade que compõem a indústria brasileira. Ainda que a desindustrialização absoluta não tenha se manifestado plenamente, a manutenção da trajetória atual de seu enfraquecimento levará, sem dúvida, à sua ocorrência em poucos anos.

A situação de perda de competitividade estrutural, associada ao comprometimento da capacidade de produzir relaçóes intersetoriais e/ou inter-regionais, deve ser vista, contudo, como expressão deste processo mais amplo de desindustrialização precoce. Em razão das diversas facetas em que se reveste a fragilização da indústria, faz-se necessário reconhecer que o processo de desindustrialização assume caráter sistêmico, em que a sua regressividade produtiva é uma manifestação atual do problema e que no momento futuro - talvez não tâo longo - tende a se encaminhar para sua diminuição absoluta como gerador de empregos e de VAB na economia brasileira em contexto de fragilização de elos internos às cadeias produtivas e das relaçôes produtivas inter-regionais.

A expressão territorial desse processo, assunto de principal interesse deste estudo, tende a assumir, como se verá ao longo dos vários capítulos deste livro, caráter igualmente heterogêneo e multifacetado. Contudo, pode-se afirmar pela consolidação de um padrão de expansão extensiva da indústria no qual o território e os recursos naturais nele localizados assumem dimensão especial.

\subsection{Território e indústria: velha relação, novas determinações}

As preocupaçôes com a dinâmica de ocupação do território brasileiro pela indústria voltaram com muita força ao debate nacional. Consolidadas as evidências de regressão da estrutura industrial longamente construída no país, quais seriam, pois, as manifestaçóes regionais desse processo? $\mathrm{O}$ enfraquecimento da indústria como motor dinâmico da economia nacional produziria um vetor favorável à desconcentração econômica regional ou, pelo contrário, tenderia a concentrar ainda mais as atividades de maior valor agregado dos grupos remanescentes da indústria e dos setores terciários modernos nas áreas mais estabelecidas do país?

Quando os primeiros sinais de enfraquecimento da indústria começaram a surgir ainda no início dos anos 1990, motivados pelas medidas de abertura comercial e financeira implementadas pelos governos Collor e depois Fernando Henrique Cardoso destinadas a aumentar a competitividade da economia nacional, os estudos sobre a questão regional apontaram para uma tendência em curso de "quebra da integração do mercado nacional" (Cano, 1998) e de "fragmentação da economia nacional" (Pacheco, 1998). Estes processos seriam muito danosos para a trajetória de desconcentração produtiva que passou ocorrer entre 1970 e 1985 depois de longo período de preocupante concentração de atividades industriais na economia paulista. 
Ambas visóes assumem que o forte e amplo processo de abertura da economia nacional do período imporia perdas à indústria, considerada menos competitiva diante dos padróes internacionais, e levaria a quebra de elos intersetoriais e inter-regionais prevalecentes até aquele momento. Sinalizavam que, estabelecida a abertura comercial e financeira em caráter rápido e irrestrito, as economias regionais voltariam - tal como no modelo primário exportador - a se relacionar diretamente com o exterior para realizar suas compras de insumos, bens e serviços levando a uma redução das trocas inter-regionais com consequentes danos à expansão do mercado interno.

Outra tese com grande aceitação no debate regional ainda nos anos 1990 foi a de "desconcentração concentrada" elaborada por Diniz (1993). Este autor apresentou evidências de que a desconcentração produtiva entre 1970 e 1991 assumia uma forma territorial específica para além das suas manifestaçóes macrorregionais. Adotando a microrregião do IBGE como unidade territorial de análise - portanto, se afastando da clássica análise de macrorregiâo ou estado - o estudo conseguiu demonstrar que a atividade industrial perseguia um padrão relativamente concentrado de desconcentração em torno da economia industrial paulista.

A investigação delimitou um território chamado de "polígono da indústria" representado por microrregióes com mais de 10 mil empregos na indústria de transformação - as quais dariam corpo ao núcleo substantivo da estrutura industrial brasileira em termos de dinâmica de valor agregado e produtividade, sendo chamadas de aglomeraçóes industriais relevantes (AIRs) - delimitadas e circunscritas entre as áreas metropolitanas de Belo Horizonte, São Paulo, Curitiba e Porto Alegre. Em 1970, o número de AIRs no país era de 33; em 1980, passou para 76; e, finalmente, em 1991 a quantidade chegou a 90 AIRs. Em torno de $85 \%$ delas se encontravam na área delimitada pelo referido polígono, isto é, preferencialmente nas regiôes Sudeste e Sul do país. Esta nova perspectiva analítica permitiu concluir que não apenas o processo de desconcentração encontrava limites territoriais bem definidos, mas também apontava para uma possível restruturação competitiva da indústria. Esta, se viesse a ocorrer, aumentaria ainda mais a concentração regional.

Todas as três teses elencadas anteriormente convergiam, portanto, para a inquietação com o fim da desconcentração que tomou forma entre 1970 e 1985 e para a emergência de um novo ciclo de reconcentração produtiva. $\mathrm{O}$ tom que se estabeleceu no debate acadêmico e governamental na década de 1990 e em anos posteriores foi de pessimismo e redobrada vigilância com os desdobramentos e efeitos da política econômica e produtiva nacional sobre as regióes de menor desenvolvimento e alvo de políticas regionais explícitas.

De maneira preliminar, pode-se adiantar que o emprego industrial continuou, nas décadas de 1990 e 2000, uma marcha de desconcentração regional que 
veio favorecer as áreas de menor desenvolvimento, embora sem que o padrão de concentração no polígono tenha sido desfeito. Estudos de Saboia $(2001 ; 2013)$ realizados em dois momentos distintos e também centrados nas AIRs apontaram para uma expansão significativa do número de aglomeraçôes industriais nas regiôes Centro-Oeste, Norte e Nordeste. A motivação para a emergência de novas AIRs nestas últimas regióes tem sido, no entanto, distinta do que se esperava: no Centro-Oeste, as aglomeraçóes industriais estão diretamente relacionadas à expansão da economia de agroexportáveis; na regiáo Norte, a mineração tem papel relevante; e no Nordeste, os incentivos fiscais, os recursos dos fundos constitucionais regionais (Fundo Constitucional de Financiamento do Nordeste - FNE) têm sido vistos como determinantes para a localização industrial.

Neste estudo, em seus capítulos subsequentes, realiza-se esforço de ampliação dos questionamentos sobre as novas formas de localizaçáo da indústria e se nutre do conceito das AIRs para verificação atualizada da dinâmica do emprego e da produção industrial. Reconhecendo-se tributário do debate regional contemporâneo tal como alinhavado anteriormente, esta investigação aposta na hipótese de que a fase em que a economia brasileira teve a indústria como motor do crescimento dado por suas economias de escala mais robustas e sua capacidade de produzir efeitos multiplicadores mais amplos, determinados pelas relações intersetoriais e inter-regionais - encontra-se hoje com sua capacidade de recuperaçáo fragilizada, especialmente frente à expectativa de constituição de um setor lastreado em progresso técnico avançado, situação pouco provável no horizonte de decisões da política econômica dos governos federais liberais do pós-2016.

As implicaçôes para a desconcentração produtiva regional, neste novo contexto, contudo não se encontram completamente esgotadas - pois o número de AIRs continuou aumentando nos anos recentes em todas as Grandes Regiôes a despeito da consolidação da regressão produtiva - mas estão relacionadas com forças de estímulo de contornos imprecisos e incertos.

Ora o surgimento de novas aglomeraçôes industriais em territórios fora do polígono ocorre por força de orientações de políticas e de investimentos infraestruturais feitos no passado recente, como nas regiôes Centro-Oeste e Norte (hidrelétricas, rodovias, ferrovias, hidrovias), ora por conta de estímulos da demanda mundial por commodities agrícolas (cerrados do Centro-Oeste e do Nordeste), de carnes (regiōes Centro-Oeste e Sul), minerais (metálicos em Minas Gerais e na Amazônia) e petróleo (região Sudeste), e finalmente, são motivados pela crescente importância que passam a assumir os incentivos fiscais e recursos dos fundos constitucionais de financiamento (FCFs) na estratégia das plantas industriais em estágio de perda de competividade estrutural. 
Os resultados mais discerníveis no quadro atual devem, no entanto, ser devidamente pontuados frente às teses predominantes até então. A consolidação da desindustrialização ainda que relativa, mas acompanhada de regressão produtiva em direção a setores cujo diferencial competitivo são os recursos naturais e a mão de obra, tem implicado mais fracas relaçóes de troca intersetoriais e inter-regionais. No decorrer deste processo, mantém-se o predomínio na grande região do polígono da atividade industrial (Sudeste-Sul) das indústrias de mais elevada intensidade tecnológica (os grupos industriais de tecnologia diferenciada, intensivos em escala e baseados em ciência). Demonstrando, desse modo, que as economias de aglomeração desta área preferencial, diante do nível superior de infraestrutura instalada, do capital humano e do nível de renda média mais elevado, continuam relevantes para atrair empreendimentos de maior valor agregado.

Para as regióes da periferia e alvo preferencial de políticas regionais, consolida-se um vetor de aparecimento de novas áreas de industrialização no Centro-Oeste e no interior do Nordeste. A atividade industrial tem se mostrado, nesta etapa recente, predominantemente relacionada a grupos intensivos em recursos naturais e mão de obra acionados pelo ciclo de commodities agrominerais, por incentivos fiscais estaduais e municipais, e por recursos públicos das políticas de fomento setorial - Banco Nacional de Desenvolvimento Econômico e Social (BNDES) - e das políticas regionais - FNE, Fundo Constitucional de Financiamento do Norte (FNO) e Fundo Constitucional de Financiamento do Centro-Oeste (FCO) - geridos pelos bancos regionais (no Nordeste, o Banco do Nordeste; na regiáo Amazônica, o Banco da Amazônia (Basa); e no Centro-Oeste, pelo Banco do Brasil - BB).

A força das determinaçóes produtivas no território se fez acompanhar de correspondentes fluxos demográficos, os quais são relevantes por suas implicações para o desenho e a implementação de políticas públicas, em particular, das regionais. Do ponto de vista da composição populacional brasileira, as áreas de fronteira de recursos naturais continuam sua trajetória de expansão relativa de contingentes populacionais. Os dados do IBGE para os Censos Demográficos 2000 e 2010 e de estimativas para 2019 são apresentados a seguir. As regiôes Norte e Centro-Oeste aumentam seu peso no total da população brasileira entre 2000, 2010 e 2019 de, respectivamente, $7,6 \%, 8,3 \%$ e $8,8 \%$ para o Norte; e $6,9 \%, 7,4 \%$ e $7,8 \%$ para o Centro-Oeste. A regiāo Nordeste, por sua vez, mantém sua trajetória de longo prazo de queda relativa de sua população passando de 28,1\% em 2000 para 27,8\% em 2010 e 27,2\% em 2019. Também as regióes Sul e Sudeste reduzem suas participações relativas de 14,6\% em 2000 para 14,4\% em 2010 e 14,3\% em 2019 para o Sul, ao passo que a região Sudeste teve sua participação diminuída de 42,6\% em 2000 para 42,1\% em 2010 e manteve-se em 42,1\% em 2019. 
Quanto aos movimentos migratórios da população, o que se percebe nas décadas recentes é a consolidação do novo vetor migratório em direção às áreas de produção de commodities agrícolas da região Centro-Oeste e manutenção do estado de São Paulo como polo tradicional de recepção de migrantes. A mensuração dos saldos migratórios, conforme Carmo e Camargo (2018), aponta para fortes saídas líquidas de migrantes da região Nordeste: entre 2000 e 2005 as saídas líquidas foram de 764 mil pessoas e no período posterior, de 2005 a 2010, foram de 701 mil. Os estados da regiáo que apresentam maiores saídas líquidas entre 2005 e 2010 são respectivamente: Bahia (237 mil), Maranhão (165 mil), Alagoas (76 mil), Pernambuco (75 mil), Piauí (70 mil), Ceará (68 mil) e Paraíba (29 mil).

Como áreas preferenciais de recepção estão as regiōes Sudeste e Centro-Oeste. $\mathrm{Na}$ primeira, as entradas líquidas estiveram no patamar de 458 mil entre $2000 \mathrm{e}$ 2005 e com redução para 325 mil no período 2005-2010. O estado de São Paulo continua sendo um importante receptor de população e sendo responsável por $78,5 \%$ das entradas líquidas regionais: foram ganhos líquidos de 339 mil entre 2000 e 2005 e de 256 mil entre 2005 e 2010.

No caso da região Centro-Oeste, nos períodos 2000-2005 e 2005-2010, os ganhos líquidos de migrantes passaram de, respectivamente, 261 mil para $263 \mathrm{mil}$ entre os dois períodos considerados. O estado de Goiás tem sido o local preferencial de entrada dos migrantes nesta região, com 202 mil e 208 mil, respectivamente, nos períodos 2000-2005 e 2005-2010. No último quinquênio, este estado sozinho respondeu por $79 \%$ do total líquido dos entrantes regionais.

$\mathrm{Na}$ regiāo Norte, o saldo líquido geral tem sido positivo, mas baixo. De 2000 a 2005, as entradas líquidas foram de 62 mil migrantes que se destinaram predominantes para Roraima (33,3 mil), Amazonas (30,9 mil), Amapá (13 mil), Tocantins (12,9 mil) e Rondônia (10,6 mil). Por sua vez, houve saídas líquidas do Pará (-52,2 mil) e do Acre (-2,4 mil). No quinquênio seguinte, de 2005 a 2010, as entradas líquidas regionais ficaram em 13,4 mil distribuídas por estados da seguinte forma: Amapá com ganhos líquidos de 21,8 mil migrantes, Amazonas com 20,1 mil, Rondônia com 12,2 mil entrantes líquidos, Tocantins com 8,6 mil e novamente Pará (-39,8 mil) e Acre (-0,8mil) com perdas líquidas.

Para as regiōes antes comentadas, os padrões de saldos migratórios líquidos são relativamente estáveis entre os dois quinquênios analisados, isto é, regiōes com saldos positivos (entradas líquidas) no primeiro período permanecem assim no segundo. Do mesmo modo, para as regiōes (ou estados) que apresentaram saldos líquidos negativos (saídas) em um período, estas se mantiveram assim no subsequente.

Não obstante, esse padrão não se estabeleceu na região Sul do país. Nesta, houve saídas líquidas de migrantes entre 2000 e 2005 de -19,2 mil. Responderam por este comportamento as perdas líquidas dos estados do Paraná (-39,7 mil) e 
Rio Grande do Sul (-39,5 mil), na contramão, Santa Catarina apresentou entradas líquidas de migrantes $(59,9$ mil). No quinquênio subsequente, a região como um todo apresenta ganhos líquidos de 76,3 mil migrantes. Houve forte incremento positivo em Santa Catarina com ganhos de 172,4 mil e perdas líquidas no estado do Rio Grande do Sul (-74,6 mil) e em menor medida do Paraná (-21,5 mil).

\section{GOVERNO E TERRITÓRIO NO PERÍODO 2000-2018: POLÍTICAS PRODUTIVAS E TERRITORIAIS}

A atuação governamental nesse período tem, sem dúvida, papel relevante para a consolidação de algumas trajetórias de ocupação do território nacional. Depois de um período de numerosas reformas econômicas visando à reestruturação do Estado brasileiro, as quais deram relevo para privatizaçóes, desregulamentaçóes, abertura comercial e financeira ao longo da década de 1990, veio a se estabelecer, paulatinamente, nova orientação de políticas federais a partir de 2003, quando coincidem o início do boom de commodities e a chegada ao Executivo federal de uma frente política de matiz desenvolvimentista.

Na maior parte da década de 1990, a predominância de restriçóes fiscais, de um lado, e a explícita orientação para minimização da presença do governo em assuntos de investimento, de outro lado, resultaram em escolhas governamentais de investimentos em infraestruturas de logística e transportes direcionados para os Eixos Nacionais de Integração e Desenvolvimento (Enids), os quais foram propostos no programa Brasil em Ação (Plano Plurianual - PPA 1996-1999) e, subsequentemente, no programa Avança Brasil (PPA 2000-2003). As potencialidades apontadas pela demanda externa sobre setores de agrominerais foram apresentadas na forma de projetos de investimento na modalidade de parcerias público-privadas (PPPs) ou eminentemente privadas, como saídas territoriais para a crise de crescimento.

Os resultados ficaram aquém do esperado. Capitais privados tiveram pouco interesse na realização de investimento previsto, ora porque o retorno econômico não se apresentou razoável em um contexto econômico de forte instabilidade e vulnerabilidade a choques externos - como se comprovou com as crises financeiras no México em 1995 e em diversos países do leste asiático em 1997 e 1998: Hong Kong, Malásia, Cingapura, Coreia do Sul, Tailândia e Indonésia, todos tiveram fortes quedas nos PIBs (superiores a 6\% negativos) após ataques especulativos nos mercados financeiros ${ }^{4}-$, ora porque os arranjos regulatórios não estavam bem definidos ou estruturados. ${ }^{5}$ De todo modo, ainda que a estratégia de investimentos em eixos de logística para exportação tivesse tido êxito, vários especialistas têm apontado que a sua consequência sobre a dinâmica territorial resultou na criaçáo e presença de 
enclaves regionais de exportação com poucas ligaçóes setoriais e regionais. Segundo Brandão (2020, p. 157-158), as consequências mais visíveis sobre o território na década de 1990 foram: "As heterogeneidades inter e intrarregionais, sobretudo essas últimas, cresceram muito. Ampliaram-se ilhas de produtividade e polos de competitividade, de produção e exportação de alguns produtos, em alta e vulnerável especialização regressiva, sobretudo em commodities."

$\mathrm{Na}$ escala estadual de governo, a privatização de bancos públicos no âmbito da federalização das dívidas estaduais reduziu a capacidade destes governos de levar adiante projetos de investimento e/ou apoiar com crédito empreendimentos privados. Desse modo, os governos subnacionais se encontraram fortemente impedidos de realizar estratégias próprias de investimento. A guerra fiscal por investimentos privados se tornou um mecanismo não apenas comum, mas também muito generalizado, neste período, como forma de atração de empreendimentos produtivos (Vieira, 2012).

Somente a partir de 2003 e até, pelo menos, 2014, em um cenário fiscal mais benigno, se configurou uma estratégia de desenvolvimento mais assertiva e com a preocupação de recompor as capacidades governamentais de planejamento e implementação de políticas perdidas na década anterior.

Nesse novo momento, foi possível recolocar no horizonte do planejamento do Estado e dos empreendedores privados a necessidade de implementar e articular um conjunto de políticas sociais, setoriais e regionais de reconhecido impacto sobre o crescimento econômico e as melhorias das condiçóes sociais da população. Inicialmente, a partir de 2003, uma política de fortalecimento do salário mínimo como referência para as remuneraçôes pagas pelo setor privado, bem como para as aposentadorias pagas pelo governo, passou a elevar paulatinamente a renda real dos trabalhadores dos estratos inferiores de remuneraçóes. No seu conjunto, o aumento da renda do trabalho permitiu a expansão nos anos subsequentes da renda interna em diversas localidades do país, em particular daquelas em que o número de aposentados e idosos é maior.

Em 2007, com o lançamento do Programa de Aceleração do Crescimento (PAC), o governo federal passou a coordenar um conjunto de investimentos de grande alcance setorial e regional cujo montante inicial se aproximava de $\mathrm{R} \$$ 500 bilhôes à época. $\mathrm{O}$ programa tinha como objetivo aumentar o gasto público federal em investimento e sinalizar para o setor privado uma carteira de projetos estruturantes para a qual o governo poderia não apenas entrar como investidor direto, mas também como facilitador do crédito para o setor privado. Durante seu período de execuçấo, que se estendeu até, pelo menos, 2015, o PAC envolveu projetos em energia elétrica e eólica, logística, recuperação de malha viária, habitação e saneamento, entre os mais relevantes. 
De um lado, o fortalecimento das políticas sociais de transferências de renda, que somadas às de educação e saúde, as quais requereram a consolidação de sistemas federativos de implementação e gestão das políticas com presença relevante de governos subnacionais veio a carrear importantes fraçóes de recursos para os governos subnacionais com impactos positivos sobre as economias locais. De outro lado, a gestão da política macroeconômica para garantir taxas elevadas de emprego, utilizando-se para tal de apoio a políticas setoriais (industriais e agrícolas), de infraestrutura e mesmo regionais e urbanas explícitas, foi fundamental para a criação de dinâmicas territoriais robustas. E, por fim, o esforço público para ampliação da relação crédito/PIB de cerca de $28 \%$ no início da década de 2000 para $45 \%$ em 2014 foi fundamental para o incentivo ao financiamento do investimento produtivo e aumento da liquidez para negócios nas diversas regióes do país.

Uma amostra desse esforço governamental pode ser observada por meio do quadro a seguir que consolida, para as tradicionais regióes-alvo de políticas regionais, isto é, Norte, Nordeste e Centro-Oeste, alguns dos principais esforços públicos voltados ao desenvolvimento socioeconômico regional. Ao retratar o comportamento de instrumentos públicos para o desenvolvimento destas regióes do país, os dados apresentados contribuem para formar uma certa ideia de que não apenas o drive externo (o boom de commodities) foi o responsável pelas determinaçôes territoriais, mas também as apostas e propostas governamentais puderam atuar para criar trajetórias alternativas e eventualmente suplementares àquelas que o mercado internacional estimulava na economia brasileira.

As fontes de recursos apresentadas correspondem a três tipologias de gastos macroeconômicos e de impactos territoriais diferentes (tabela 1). Quando são coordenados para atuar sincronicamente tendem a gerar resultados sobre o desenvolvimento socioeconômico muito relevantes. O investimento público federal corresponde ao gasto direto do governo no sistema econômico com reverberaçóes sobre a oferta do setor privado. O crédito público ao investimento privado, na forma de recursos dos fundos constitucionais de desenvolvimento das regióes e de desembolsos do BNDES, tende impactar o nível de investimento privado, pois representa financiamento de parte ou totalidade de um projeto de investimento aprovado. Os recursos chamados de "programas sociais" neste quadro correspondem a transferências governamentais feitas a famílias na forma do Programa Bolsa Família (PBF) e dos Benefícios de Prestação Continuada (BPCs) e impactam a demanda por bens de consumo nas localidades onde são destinados.

Para esse conjunto de instrumentos, o governo federal pôde decidir realizar estímulos, de um lado, sobre o investimento agregado pelo gasto direto em investimento público e pelo financiamento de parte do investimento privado e, 
de outro lado, sobre a composição de demanda agregada de consumo pela inclusão de fraçóes mais pobres e vulneráveis da população à estrutura de consumo nacional. A demanda adicional gerada por estas parcelas da população tende a influenciar, em momento subsequente, as expectativas empresariais de realização de novo investimento.

TABELA 1

Modalidades e recursos de política pública com impactos regionais ${ }^{1}$ - regiões Norte, Nordeste e Centro-Oeste

(Em R\$ bilhões de 2015)

\begin{tabular}{|c|c|c|c|c|c|c|}
\hline \multirow{2}{*}{$\begin{array}{l}\text { Região/ } \\
\text { períodos }\end{array}$} & \multirow{2}{*}{$\begin{array}{l}\text { Investimento } \\
\text { público federal } \\
\text { (A) }\end{array}$} & \multicolumn{3}{|c|}{ Crédito ao investimento } & \multirow{2}{*}{$\begin{array}{l}\text { Programas } \\
\text { sociais } \\
\text { (E) }\end{array}$} & \multirow{2}{*}{$\begin{array}{c}\text { Totais } \\
(A+D+E)\end{array}$} \\
\hline & & $\begin{array}{c}\text { Fundo } \\
\text { constitucional (B) }\end{array}$ & $\begin{array}{c}\text { Desembolsos } \\
\text { (C) }\end{array}$ & $(B+C)=(D)$ & & \\
\hline Nordeste & $\begin{array}{l}\text { Investimento } \\
\text { público }\end{array}$ & FNE & BNDES & FNE + BNDES & $P B F+B P C$ & $\begin{array}{l}\text { Subtotal } \\
\text { Nordeste }\end{array}$ \\
\hline \multirow[t]{2}{*}{$2000-2006$} & $41,0^{2}$ & 34,2 & 61,2 & 95,4 & $39,1^{3}$ & 175,5 \\
\hline & $23,4 \%$ & $19,5 \%$ & $34,9 \%$ & $54,3 \%$ & $22,3 \%$ & $100,0 \%$ \\
\hline \multirow[t]{2}{*}{$2007-2015$} & 168,2 & 122,3 & 217,4 & 339,7 & 170,1 & 678 \\
\hline & $24,8 \%$ & $18,0 \%$ & $32,1 \%$ & $50,1 \%$ & $25,1 \%$ & $100,0 \%$ \\
\hline \multirow[t]{2}{*}{ Total Nordeste } & 209,2 & 156,5 & 278,6 & 435,1 & 209,2 & 853,5 \\
\hline & $24,5 \%$ & $18,3 \%$ & $32,6 \%$ & $51,0 \%$ & $24,5 \%$ & $100,0 \%$ \\
\hline Norte & $\begin{array}{l}\text { Investimento } \\
\text { público }\end{array}$ & FNO & BNDES & FNO + BNDES & $P B F+B P C$ & $\begin{array}{l}\text { Subtotal } \\
\text { Norte }\end{array}$ \\
\hline \multirow[t]{2}{*}{$2000-2006$} & $20,2^{2}$ & 17,1 & 23,7 & 40,8 & $12,5^{3}$ & 73,5 \\
\hline & $27,5 \%$ & $23,3 \%$ & $32,2 \%$ & $55,5 \%$ & $17,0 \%$ & $100,0 \%$ \\
\hline \multirow[t]{2}{*}{ 2007-2015 } & 69,6 & 36,3 & 126,6 & 162,9 & 70,0 & 302,5 \\
\hline & $23,0 \%$ & $12,0 \%$ & $41,9 \%$ & $53,9 \%$ & $23,1 \%$ & $100,0 \%$ \\
\hline \multirow[t]{2}{*}{ Total Norte } & 89,8 & 53,3 & 150,3 & 203,6 & 82,5 & 375,9 \\
\hline & $23,9 \%$ & $14,2 \%$ & $40,0 \%$ & $54,2 \%$ & $21,9 \%$ & $100,0 \%$ \\
\hline Centro-Oeste & $\begin{array}{l}\text { Investimento } \\
\text { público }\end{array}$ & $\mathrm{FCO}$ & BNDES & $\mathrm{FCO}+\mathrm{BNDES}$ & $P B F+B P C$ & $\begin{array}{c}\text { Subtotal } \\
\text { Centro-Oeste }\end{array}$ \\
\hline \multirow[t]{2}{*}{$2000-2006$} & $14,4^{2}$ & 21,3 & 51,9 & 73,2 & $19,0^{3}$ & 106,6 \\
\hline & $13,5 \%$ & $20,0 \%$ & $48,7 \%$ & $68,6 \%$ & $17,8 \%$ & $100,0 \%$ \\
\hline \multirow[t]{2}{*}{ 2007-2015 } & 59,8 & 54,2 & 165,4 & 219,6 & 68,0 & 347,4 \\
\hline & $17,2 \%$ & $15,6 \%$ & $47,6 \%$ & $63,2 \%$ & $19,6 \%$ & $100,0 \%$ \\
\hline \multirow[t]{2}{*}{$\begin{array}{l}\text { Total } \\
\text { Centro-Oeste }\end{array}$} & 74,2 & 75,5 & 217,3 & 292,8 & 87,0 & 454,0 \\
\hline & $16,3 \%$ & $16,6 \%$ & $47,9 \%$ & $64,5 \%$ & $19,2 \%$ & $100,0 \%$ \\
\hline \multirow[t]{2}{*}{$\begin{array}{l}\text { Total } \\
\mathrm{NE}+\mathrm{NO}+\mathrm{CO}\end{array}$} & 373,2 & 285,3 & 646,2 & 931,5 & 378,7 & 1683,4 \\
\hline & $22,2 \%$ & $16,9 \%$ & $38,4 \%$ & $55,3 \%$ & $22,5 \%$ & $100,0 \%$ \\
\hline
\end{tabular}

Fontes: Para investimento público federal: Secretaria de Orçamento Federal (SOF), Ministério do Planejamento. Para os fundos constitucionais: Ministério da Integração Nacional; desembolsos do BNDES: relatórios anuais do BNDES (vários números). Para o PBF: Ministério do Desenvolvimento Socia. Para o BPC: Ministério da Previdência.

Notas: ${ }^{1}$ Valores acumulados no período 2000-2015 e subperíodos.

2 Para o investimento federal, são utilizados dados do período 2001-2006.

${ }^{3}$ O PBF tem seu início de implementação em 2004. Os dados aqui utilizados são do período 2004-2015. 
O que se apresentou, portanto, no período em termos da aplicação de recursos públicos? Nota-se a firme expansão do volume de recursos em todas as regióes e em todos as modalidades de recursos entre 2000-2006 e 2007-2015 em linha com o início de implementação do PAC em 2007.

Em termos de volumes observados, o crédito público ao investimento privado (fundos nacionais de financiamento - FCFs e BNDES) foi a modalidade de maior expressão entre as investigadas. No conjunto das três regióes, o apoio ao setor privado na forma de crédito atingiu um valor acumulado de $\mathrm{R} \$ 931,5$ bilhóes (valores de 2015), que representou o percentual de 55,3\% do total no período 2000-2015.

Os valores destinados a transferências na forma de PBF e BPC para consumo das famílias, nas três regiôes, de $\mathrm{R} \$ 378,7$ bilhôes, igualaram aos montantes de recursos federais destinados a investimento público ( $\mathrm{R} \$ 373,2$ bilhóes). Correspondem a recursos que criam, emum primeiro momento de realização do gasto, efeitos sobre a demanda de consumo e fortalecem a base econômica municipal; como efeito indireto, eles incentivam o investimento privado local. As regióes Norte e Nordeste, com maiores contingentes de pobres e miseráveis, são as que mais recebem recursos federais de transferências de rendas a pessoas. Se se tem em consideração que estas modalidades de apoio público se somam às aposentadorias rurais, o resultado conjunto é de elevado nível de transferências públicas para pessoas (e localidades) no interior das regióes citadas. O fortalecimento das economias locais/municipais nos territórios do semiárido nordestino e na Amazônia teve reverberação no crescimento econômico de inúmeras cidades médias e pequenas, conforme registram estudos recentes, como em Alves (2017).

Percebe-se, ademais, que os relevantes instrumentos da política regional explícita - os FCFs - correspondem a fontes de recursos com menor participação relativa entre as investigadas. Com $\mathrm{R} \$ 285,3$ bilhóes no período representaram apenas $16,9 \%$ do total. É uma constatação reveladora e tem muito a dizer sobre estratégias de desenvolvimento regional: aquelas que pretendem ter efeitos robustos sobre as regióes precisam contar com instrumentos e recursos adicionais do governo para serem efetivas, por si só, os montantes de recursos a elas associados no momento atual - que foram crescentes nas duas décadas passadas - não possuem, contudo, a escala para realizar a mudança estrutural requerida. A coordenação de projetos de investimento financiados pelo BNDES e dos feitos pelos FCFs torna-se necessária e, se realizada, tende a magnificar os efeitos da política regional.

Do mesmo modo, pode-se dizer que os esforços de ampliação do investimento público direto e dos recursos à disposição das famílias para consumo, geraram externalidades positivas e estímulos sobre o investimento privado nas três regiôes. 
Estas modalidades de gastos públicos elencadas não esgotam o conjunto de instrumentos efetivamente utilizados pelo governo federal à época, contudo, permitem a elaboração de uma visão sobre os traços da atuação governamental e as trajetórias dos recursos manuseados pelo governo federal no período.

Do ponto de vista da alocação setorial, as evidências, que serão mais extensivamente esmiuçadas em capítulos subsequentes, apontam para forte destinação de recursos nos ramos de atividade da agroindústria e bens de consumo leve e intermediários, seguindo, portanto, a força emitida pela orientação do drive exportador.

Os FCFs da política regional, por exemplo, destinados ao conjunto das três regióes, entre 2000 e 2015, foram mais alocados na agropecuária $(41,5 \%)$ e em serviços $(28,8 \%)$, que na indústria $(20,3 \%)$ e em infraestrutura $(9,3 \%)$, segundo Ipea (2019). Em um contexto de alocação setorial como este, que papel caberia à política regional atuar mais efetivamente para promover mudanças estruturais de grande significado? Deveriam os recursos públicos ser orientados para atividades industriais com comprovados e elevados efeitos multiplicadores setoriais e inter-regionais? Ou deveria simplesmente apoiar as atividades que o modelo determinado pela inserção externa voltado para especialização em commodities vem consolidando? Ou ainda, a política regional deveria estar orientada para a maximização do nível de emprego e renda regional e, assim, apostar em atividades intensivas em mão de obra e recursos naturais?

Os expressivos recursos públicos à disposição dessas regióes, sem dúvida, contribuíram para o fortalecimento de suas bases produtivas e permitiram o surgimento de novos espaços econômicos, seja na forma de aglomeraçóes industriais, seja simplesmente como espaços de produção agromineral em cidades de tamanho e função média nestas regiōes, assim como no restante do país. Entretanto, as opçôes de aplicação de recursos públicos poderiam ter produzido um outro tipo de orientaçấo territorial com integração de rede de cidades e fortalecimento em nível mais elevado do mercado interno?

De modo geral, a atuação governamental revigorada entre 2003 e 2014 se não conseguiu se contrapor às trajetórias de perda de relevância da indústria na economia nacional, de reestruturação produtiva ligada à produção de bens primários e dependência do ciclo externo de commodities, pôde ainda assim criar algumas trajetórias de redução de danos e reorientação de políticas e instrumentos geradores de novas soluçóes espaciais. Consideraçóes mais amplas e fundamentadas sobre o caráter de enfrentamento assumido pelas políticas públicas nesse período estão apresentadas, entre outros, em Araújo (2013), Brandão e Siqueira (2013), Steinberger (2017), Monteiro Neto et al. (2017) e Monteiro Neto (2020). Sobre a atuação com caráter de desenvolvimento regional do BNDES, a coletânea Um olhar territorial para o desenvolvimento, publicada em 2014 - e entre eles Siffert et al. (2014) sobre a Amazônia, 
Montoro et al. (2014) para a região Sul, Guimarães et al. (2014) para o Nordeste com volumes específicos e diversos estudos para as cinco macrorregiốes brasileiras, apreende a marca e o curso da experiência desta instituição no financiamento de açóes com explícitas repercussóes territoriais.

\section{CONSIDERAÇÕES FINAIS}

Mostramos nas seções precedentes de que maneiras se coloca o debate sobre o papel da indústria no desenvolvimento e na desconcentração regional brasileira hoje. Afirmamos pela escolha do conceito de "estratégia de mudança estrutural" como um meio de grande aporte compreensivo para o momento atual. Se a indústria representou este elemento ou setor de atividade capaz de produzir mudança estrutural na economia brasileira durante o período 1930-1980, seu enfraquecimento no período posterior e até o momento presente não conta com a surgimento de um outro elemento capaz de superá-la ou, alternativamente, de imprimir vigor àquelas atividades em dificuldades estruturais. Sua fraqueza, contudo, vem redefinindo a dinâmica de ocupação do território nacional pela imposição de um afastamento progressivo da indústria relativamente ao padrão dinâmico verificado no passado, ora no que se refere à sua anterior capacidade expansiva intersetorial, ora sobre seus efeitos de crescimento inter-regional.

Apontamos, ademais, que duas relevantes abordagens analíticas se prestam a clarificar o debate "indústria e território" no Brasil. A primeira é da integração do mercado nacional, que no momento atual perde força e deixa de ser um elemento propulsor do desenvolvimento regional: regióes e setores se expandem mais por estímulos externos que pelos internos e quando o fazem são pouco capazes de produzir novas ondas de estímulo sobre o restante da economia nacional. E a segunda é das forças das economias de aglomeração, que a despeito do vetor de desconcentraçáo pela via dos recursos naturais associados ao mercado externo, ainda se mostram cruciais para o entendimento da fraca intensidade com que se apresenta a desconcentração produtiva regional na indústria.

São questôes que norteiam amplamente a análise sobre as dificuldades presentes na atual economia brasileira, relacionadas aos obstáculos para a realização de uma mudança estrutural que escape da armadilha da renda média e favoreça setores e atividades de elevada produtividade e valor agregado.

Para efeito de conclusão deste capítulo inicial, registramos os principais termos do debate acadêmico, bem como identificamos os questionamentos considerados mais pertinentes para uma investigaçáo sobre a reconfiguração territorial da atividade industrial no período recente. Algumas de suas características e formas mais frequentes foram preliminarmente abordadas e apontadas de maneira a elaborar um quadro geral do esforço necessário de desdobramento das hipóteses formuladas. 


\section{REFERÊNCIAS}

ALVES, A. M. Políticas de desenvolvimento regional e rede de cidades no semi-árido: concentração, polarização e fragmentação. 2017. Tese (Doutorado) Departamento de Geografia, Universidade de Brasília, Brasília, 2017.

ARAÚJO, T. B. Ensaios sobre o desenvolvimento brasileiro: heranças e urgências. Rio de Janeiro: Editora Revan, 2000.

. Tendências do desenvolvimento regional recente no Brasil. In: BRANDÁO, C.; SIQUEIRA, H. (Orgs.). Pacto Federativo, integraçáo nacional e desenvolvimento regional. São Paulo: Ed. Fundação Perseu Abramo, 2013.

AREND, M.; SINGH, G.; BICHARRA, J. Mudança estrutural redutora da produtividade: o falling behind brasileiro. In: ENCONTRO NACIONAL DE ECONOMIA, 2016. Foz do Iguaçu, Paraná. Anais... Foz do Iguaçu: Anpec, 2016.

BACHA, E.; DE BOLLE, M. B. O futuro da indústria no Brasil: desindustrialização em debate. Rio de Janeiro: Civilização Brasileira, 2013.

BONELLI, R.; PESSOA, S.; MATOS, S. Desindustrialização no Brasil: fatos e interpretação. In: BACHA, E.; DE BOLLE, M. (Orgs.). O futuro da indústria no Brasil: desindustrialização em debate. Rio de Janeiro, RJ: Civilização Brasileira, 2013.

BRANDÃO, C. A. Território e desenvolvimento: as múltiplas escalas entre o local e o global. Campinas: Editora Unicamp, 2007.

. Dinâmicas e transformaçóes territoriais recentes: o papel da PNDR e das políticas públicas não regionais com impacto territorial. In: MONTEIRO NETO, A. (Org.). Desenvolvimento regional no Brasil: políticas, estratégias e perspectivas. Brasília: Ipea. 2020. v. 2.

BRANDÁO, C. A.; SIQUEIRA, H. (Orgs.). Pacto federativo, integraçáo nacional e desenvolvimento regional. São Paulo: Ed. Fundação Perseu Abramo, 2013.

CANO, W. Desequilíbrios regionais e concentraçáo industrial no Brasil: 19301970. São Paulo: Global; IE/Unicamp, 1985.

Desequilíbrios regionais e concentraçáo industrial no brasil, 19301995. Campinas: IE/Unicamp, 1998.

. Novas determinaçóes sobre as questóes regional e urbana após 1980. Campinas: IE/Unicamp, 2011. (Texto para Discussão, n. 193).

. A desindustrialização no Brasil. Revista Economia e Sociedade, Campinas, v. 21, p. 831-851, 2012. 
CARMO, R. L.; CAMARGO, K. C. M. Dinâmica demográfica brasileira recente: padróes regionais de diferenciação. Brasília: Ipea, 2018. (Texto para Discussão, n. 2415).

CAVALCANTE, L. R.; DE NEGRI, F. Evolução recente dos indicadores de produtividade no Brasil. In: CAVALCANTE, L. R.; DE NEGRI, F. (Orgs.). Produtividade no Brasil: desempenho e determinantes. Brasília: Ipea, 2014. v. 1. COUTINHO, L.; BELUZZO, L. G. Desenvolvimento e estabilização sob finanças globalizadas. Economia e Sociedade, n. 7, p. 129-154, 1996.

DINIZ, C. C. Desenvolvimento poligonal no Brasil: nem desconcentração, nem contínua polarização. Nova Economia, Belo Horizonte, v. 3, n. 1, p. 35-64, set. 1993. Disponível em: <https://bit.ly/3fYDLbP>.

FURTADO, C. Desenvolvimento e subdesenvolvimento. Rio de Janeiro: Editora Fundo de Cultura, 1961.

GALA, P. Complexidade econômica: uma nova perspectiva para entender a antiga questão da riqueza das nações. São Paulo: Contraponto, 2017.

GALVÃO, A. C.; BRANDÃO, A. C. Fundamentos, motivaçôes e limitaçôes da proposta governamental dos "Eixos Nacionais de Integração e Desenvolvimento". In: GONÇALVES, M. F. et al. (Orgs.). Regióes e cidades, cidades nas regióes: o desafio urbano-regional. São Paulo: Editoria Unesp, 2003.

GUIMARÁES, P. F. et al. (Orgs.). Um olhar territorial para o desenvolvimento: Nordeste. Rio de Janeiro: BNDES, 2014.

IBGE - INSTITUTO BRASILEIRO DE GEOGRAFIA E ESTATÍSTICA. Estatísticas Demográficas dos Censos de 1872 a 2010. [s.l.]: IBGE, [s.d.]. Disponível em: <https://bit.ly/3pujLQ2>. Acesso em: 12 mar. 2020.

IPEA - INSTITUTO DE PESQUISA ECONÔMICA APLICADA. Indicadores regionais. Boletim Regional, Urbano e Ambiental, n. 21, jul-dez, 2019.

KALDOR, N. Causes of the slow rate of economic growth of the United Kingdom. London: Cambridge University Press, 1966.

. The Case for Regional Policies. Scottish Journal of Political Economy, v. 17, n. 3, p. 337-348, 1970.

LEWIS, W. A. Economic development with unlimited supplies of labour. The Manchester School, v. 22, n. 2, p. 139-191, 1954.

MACEDO, F. C. Inserçáo externa e território: impactos do comércio exterior da dinâmica regional e urbana no Brasil (1989-2008). 2010. Tese (Livre Docência) Instituto de Economia, Universidade Estadual de Campinas, Campinas, 2010. 
MARCONI, N.; ROCHA, I.; MAGACHO, G. Sectoral capabilities and productive structure: an input-output analysis of the key sectors of the Brazilian economy. Brazilian Journal of Political Economy, v. 36, n. 3, p. 470-492, 2016.

MOLLO, M. L. R.; TAKASAGO, M. O debate desenvolvimentista no Brasil e o papel da indústria: novos resultados de antigas liçóes. Economia e Sociedade, v. 28 , n. 3, p. $885-904,2019$.

MONTEIRO NETO, A. Desenvolvimento regional em crise: políticas econômicas liberais e restriçóes à intervenção estatal no Brasil dos anos 1990. 2005. Tese (Doutorado) - Instituto de Economia, Universidade Estadual de Campinas, Campinas, 2005.

. (Org.). Desenvolvimento regional no Brasil: políticas, estratégias e perspectivas. Brasília: Ipea, 2020. v. 2.

MONTORO, G. C. F. et al. (Orgs.). Um olhar territorial para o desenvolvimento: Sul. Rio de Janeiro: BNDES, 2014.

MONTEIRO NETO, A.; SILVA, R. O. Desconcentraçáo territorial e reestruturação regressiva da indústria no Brasil: padróes e ritmos. Brasília: Ipea, 2018. (Texto para Discussão, n. 2404).

MONTEIRO NETO, A. et al. Desenvolvimento regional brasileiro: dilemas e perspectivas neste início de século XXI. In: MONTEIRO NETO, A.; CASTRO, C.; BRANDÃO, C. (Orgs.). Desenvolvimento regional no Brasil: políticas, estratégias e perspectivas. Brasília: Ipea, 2017.

MORCEIRO, P. C. Vazamento de demanda setorial e competitividade da indústria de transformação brasileira. São Paulo: FEA/USP, 2016. (Texto para Discussão, n. 12).

MYRDAL, G. Economic Theory and Underdeveloped Regions. London: Duckworth. 1957.

NASSIF, A. Há evidências de desindustrialização no Brasil? Revista de Economia Política, n. 28, v. 1, p. 72-96, jan.-mar. 2008.

OREIRO, J. L.; MARCONI, N. Teses equivocadas no debate sobre desindustrialização e perda de competitividade da indústria brasileira. Revista Necat, v. 3, n. 5, p. 24-48, 2014.

PACHECO, C. A. Fragmentação da naçáo. Campinas: Unicamp, 1998.

PREBISCH, R. El desarrollo económico de la América Latina y algunos de sus principales problemas. Desarrollo Econômico, v. 26, n. 103, p. 479-502, 1949.

SABOIA, J. A dinâmica da descentralizaçáo industrial no Brasil. Rio de Janeiro: IE/UFRJ, 2001. (Texto para Discussão, n. 451). 
A continuidade do processo de desconcentração regional da indústria brasileira nos anos 2000. Nova Economia, Belo Horizonte, v. 23, n. 2, p. 219 278, maio-ago. 2013. Disponível em: <https://bit.ly/3w3SZBY>.

SAMPAIO, D. Desindustrialização e desenvolvimento regional no Brasil (19852015). Capítulo 12. In: MONTEIRO NETO, A.; CASTRO, C.; BRANDAO, C. A. (Orgs.). Desenvolvimento regional no Brasil: políticas, estratégias e perspectivas. Brasília: Ipea, 2017.

SAMPAIO, D. P. Desindustrializaçáo e estruturas produtivas regionais no Brasil. 2015. Tese (Doutorado) - Instituto de Economia, Universidade Estadual de Campinas, Campinas, 2015.

SIFFERT, N. et al. (Orgs.). Um olhar territorial para o desenvolvimento: Amazônia. Rio de Janeiro: BNDES, 2014.

SQUEFF, G. Desindustrialização: luzes e sombras no debate brasileiro. Brasília: Ipea, 2012. (Texto para Discussão, n. 1747). Disponível em: <goo.gl/zvyCz5>.

STEINBERGER, M. (Org.). Território, agentes-atores e políticas públicas espaciais. Brasília: Editora Ler, 2017.

VIEIRA, D. J. Um estudo sobre a guerra fiscal no Brasil. 2012. Tese (Doutorado) Instituto de Economia, Universidade Estadual de Campinas, Campinas, 2012.

VITAL DA COSTA, K. G.; NEVES, F. F. Padrōes de interdependência setorial da estrutura produtiva brasileira entre 2000 e 2015: uma análise insumo-produto a partir da decomposição da matriz de Leontief. In: ENCONTRO ANUAL DE ECONOMIA POLÍTICA, 2016. São Bernardo do Campo, São Paulo. Anais... São Bernardo do Campo: Anpec, 2016.

\section{BIBLIOGRAFIA COMPLEMENTAR}

HIRSCHMAN, A. O. Estratégia do desenvolvimento econômico. Rio de Janeiro: Editora Fundo de Cultura, 1961.

KUZNETS, S. Economic growth of nations: total output and production structure. Cambridge: Harvard University Press, 1971. 